\title{
Impaired resistance in early secondary Nippostrongylus brasiliensis infections in mice with defective eosinophilopoeisis
}

\author{
Michelle L. Knott ${ }^{\text {a }}$, Klaus I. Matthaei ${ }^{\text {b }}$, Paul R. Giacomin ${ }^{\text {a }}$, Hui Wang ${ }^{\text {a }}$, \\ Paul S. Foster ${ }^{\text {b,c }}$, Lindsay A. Dent ${ }^{\text {a,* }}$ \\ ${ }^{a}$ School of Molecular and Biomedical Science, The University of Adelaide, North Terrace, Adelaide, SA 5005, Australia \\ ${ }^{\mathrm{b}}$ Division of Molecular Bioscience, John Curtin School of Medical Research, The Australian National University, Canberra, Australia \\ ${ }^{\mathrm{c}}$ School of Biomedical Sciences, Faculty of Health, University of Newcastle, Newcastle, Australia
}

Received 16 January 2007; received in revised form 30 March 2007; accepted 16 April 2007

\begin{abstract}
Eosinophils are an important feature of immune responses to infections with many of the tissue-invasive helminth parasites. The cytokine IL-5 and a high-affinity double GATA-binding site within the GATA-1 promoter are critical for eosinophilopoiesis. In this study, we believe we demonstrate for the first time that defects in eosinophilopoiesis are associated with impaired resistance to Nippostrongylus brasiliensis. Primary and secondary infections were established in wildtype (WT), IL- $5^{-/-}$and $\Delta$ dblGATA mice. Resistance to secondary infections was impaired in IL- $5^{-/-}$and $\Delta$ dblGATA mice, with significantly more larvae able to reach the lungs 2 days p.i. Pulmonary inflammation was minimal in all strains in the first 2 days of both primary and secondary infections, suggesting that eosinophil-dependent resistance occurred before larvae reached this site. Intestinal worm burdens and/or parasite egg production in primary infections were greater in animals with defective eosinophilopoiesis. While larvae did reach the gut by day 3 of secondary infections of WT and IL- $5^{-1-}$ mice, worms were expelled by day 7, even in the complete absence of eosinophils in tissues of the small intestine. This and our previous studies indicate that $N$. brasiliensis are likely to be exquisitely sensitive to attack by eosinophils soon after entry into the skin. Eosinophils in the gut may make a modest contribution to resistance on first exposure to the parasite, but are not required for expulsion in either primary or secondary infections. In order to mount an effective immune response it may be vital for the host to identify and attack the parasite before it implements immune evasion strategies and migrates to other anatomical sites. These observations may be of particular significance for the development of successful vaccines against hookworms and other nematodes.
\end{abstract}

(c) 2007 Australian Society for Parasitology Inc. Published by Elsevier Ltd. All rights reserved.

Keywords: IL-5; Eosinophil; Nippostrongylus brasiliensis; Nematode; Skin; Primary and secondary infections; Lungs; Gut

\section{Introduction}

Gastrointestinal helminth infections are amongst the most common chronic diseases of humans, causing significant morbidity and contributing to developmental and intellectual retardation in children (Chan et al., 1994). Immune responses to tissue-invasive parasitic helminths can share a number of features. A bias towards Type 2 cytokine production is frequently seen and cells

\footnotetext{
* Corresponding author. Tel.: +618 83034155; fax: +618 83034362.

E-mail address: lindsay.dent@adelaide.edu.au (L.A. Dent).
}

such as neutrophils, eosinophils and mast cells are usually recruited and activated (Kay et al., 1985). Although eosinophils are often recruited in large numbers in response to tissue invasive parasitic helminths, the roles of these cells remain controversial (Behm and Ovington, 2000; Meeusen and Balic, 2000; Lee and Lee, 2005). In vitro, eosinophils can adhere to helminth larvae (Hagan et al., 1985; Desakorn et al., 1987; Giacomin et al., 2005), releasing granule contents (Glauert et al., 1978; Ackerman et al., 1990; Hamann et al., 1990) and in some instances killing larvae by mechanisms that have yet to be adequately defined (Lee, 1991; Lee and Lee, 2005). 
However, the role of eosinophils in vivo is less well established. Eosinophils often accumulate and degranulate around tissue-invading helminths (Taliaferro and Sarles, 1939; Sugane and Oshima, 1982; Daly et al., 1999; Rajan et al., 2002), but do not necessarily kill the parasites (Parsons et al., 1993; Dent et al., 1999) and in some circumstances may even enhance parasite survival (Dent et al., 1997a,b).

Nippostrongylus brasiliensis is a natural parasite of mice and other rodents and is useful as an experimental model because it has a life cycle similar to hookworms and Strongyloides stercoralis. Larvae can enter the host through the skin and migrate to the lungs within 24 $48 \mathrm{~h}$. Larvae then move to the small intestine, undergo final maturation into adult worms and produce eggs (Kassai, 1982). Studies of $N$. brasiliensis infections in mice over-expressing IL-5 indicate that eosinophils can be important for protection during the early stages of primary infection (Dent et al., 1997b, 1999). Eosinophils are seen in the skin within $2 \mathrm{~h}$ of infection and appear to be involved in trapping larvae at this site. Compared with primary infections in wildtype (WT) animals, numbers of lung-stage larvae, intestinal worms and eggs are significantly reduced in IL-5 transgenic mice (Daly et al., 1999; Dent et al., 1999). It would therefore appear that if available in sufficient numbers, eosinophils can contribute to protection against some helminths. Rodent hosts are strongly resistant to secondary $N$. brasiliensis infections and although eosinophils are recruited (Ogilvie and Parrott, 1977; Egwang et al., 1984; Finkelman et al., 1994; Sakamoto et al., 2004), the mechanism of this acquired resistance is largely unknown.

Since we had previously established that eosinophils were protective within the first $24 \mathrm{~h}$ of infection, in the current study we investigated the impact of impaired eosinophilopoiesis on all stages of $N$. brasiliensis migration and maturation. Both primary and secondary infections were examined in IL- $5^{-/-}$mice and in $\triangle$ dblGATA mice ( $\mathrm{Yu}$ et al., 2002; Humbles et al., 2004). IL-5 is the major growth, differentiation and survival factor for eosinophils (Sanderson, 1988; Yamaguchi et al., 1988; Coffman et al., 1989; Dent et al., 1990) and although

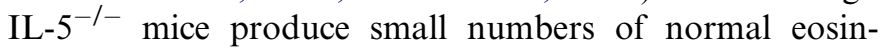
ophils, they do not show tissue eosinophilia in response to challenge with allergens or parasites (Foster et al., 1996; Kopf et al., 1996; Matthaei et al., 1997; Vallance et al., 2000; Ramalingam et al., 2003). $\Delta$ dblGATA mice have a more profound defect in eosinophilopoiesis due to a deletion of the double GATA site in the GATA-1 locus and no eosinophils are seen in either untreated animals, in the lungs of mice sensitized to and challenged with allergen, or in $\triangle$ dblGATA mice expressing the IL5 transgene ( $\mathrm{Yu}$ et al., 2002; Humbles et al., 2004). This study shows that mice with defects in eosinophilopoiesis had impaired resistance to $N$. brasiliensis in the intestinal phase of primary infections and in the early pre-lung phase of secondary infections.

\section{Materials and methods}

\subsection{Animals}

Heterozygous male and female $\mathrm{CBA} / \mathrm{Ca}$ mice with approximately eight copies of the IL-5 transgene (Dent et al., 1990), BALB/c mice with approximately 50 copies of the IL-5 transgene (Dent, 2002) and their WT littermates were bred in the Laboratory Animal Services facility at the University of Adelaide. A homozygous targeted IL-5 gene deletion (IL-5 ${ }^{-/-}$) (Kopf et al., 1996) was backcrossed from $\mathrm{C} 57 \mathrm{BL} / 6$ to the CBA/H background for 20 generations at the John Curtin School of Medical Research and then maintained as a closed line at The University of Adelaide. BALB $/ \mathrm{c} \mathrm{IL-5}{ }^{-/-}$and $\Delta$ dblGATA (Yu et al., 2002) mice were bred at the John Curtin School of Medical Research, the latter from foundation stock kindly provided by Drs. Stuart Orkin and Craig Gerard. All mice were closely age-matched within experiments. Hooded Wistar rats used for passage of $N$. brasiliensis were obtained from Laboratory Animal Services at the University of Adelaide. Animals were handled according to Animal Ethics Committee guidelines of the University of Adelaide.

\subsection{Parasite infection of mice}

Nippostrongylus brasiliensis L3 were obtained by the faecal culture method as described previously (Daly et al., 1999), washed twice in MilliQ water and once in mouse osmolality PBS (MPBS) (Sheridan and Finlay-Jones, 1977), and each experimental animal received 500 or 750 L3 by either intra-air pouch or s.c. injection, respectively. L3 were injected at the base of the neck or into air pouches in the mid-dorsal skin using a 19-gauge needle. Mice in secondary infection groups were injected s.c. with 500 or 750 L3 and 3 weeks later, after clearance of the primary infection, mice were challenged with 500 or $750 \mathrm{~L} 3$.

\subsection{Recovery of lung larvae}

Mice were sacrificed by $\mathrm{CO}_{2}$ asphyxiation on day 2 p.i., lungs were removed, washed in saline, finely minced and incubated in saline at $37^{\circ} \mathrm{C}$ for at least $2 \mathrm{~h}$ to promote larval migration out of lung fragments. Larvae were then counted using a dissecting microscope.

\subsection{Faecal egg counts}

Faecal egg counts were performed on day 6 p.i. One large faecal pellet was collected from each animal and hydrated in $0.4 \mathrm{ml}$ of saline for 10-15 min before disaggregation. To promote egg flotation, $0.4 \mathrm{ml}$ of saturated sodium chloride was added. A Whitlock Universal slide chamber (J A Whitlock \& Co., NSW, Australia) was loaded with the whole sample and total egg counts were performed at $10 \times$ magnification using a compound light microscope. 


\subsection{Intestinal worm recovery}

The small intestine was removed 3 or 7 days p.i., placed in saline and split longitudinally with sharp scissors. Samples were incubated for at least $1 \mathrm{~h}$ at $37^{\circ} \mathrm{C}$ to encourage worm detachment from the intestinal wall and total worm numbers were then counted using a dissecting microscope. The small intestine was also examined to ensure that worms still attached to the gut wall were included in counts.

\subsection{Generation and analysis of infections in skin air pouches}

Air pouches were generated in the shaved dorsal skin of anaesthetised mice by s.c. injection of $2.5 \mathrm{ml}$ of filtered air $(0.22 \mu \mathrm{m}$ filter, Millipore, Bedford, MA, USA) through a 25 -gauge needle. Three days later pouches were re-inflated with $2 \mathrm{ml}$ of sterile air and larvae were injected after a further 2 days. Mice were sacrificed by $\mathrm{CO}_{2}$ asphyxiation 0 or $4 \mathrm{~h}$ p.i. with $500 \mathrm{~L} 3$ and the pouches were lavaged four times with $2 \mathrm{ml}$ of MPBS using a 19-gauge needle and syringe. Total viable cells in air pouch fluid were enumerated using trypan blue exclusion and a haemocytometer. Pouch exudate cells were cytocentrifuged onto glass slides and stained with Giemsa (BDH Chemicals, Gurr, Australia). Differential leukocyte counts were estimated by enumeration of a minimum of 200 cells per sample using oil immersion light microscopy. Recovered larvae were resuspended in MPBS and counted using a dissecting microscope.

\subsection{Histology}

Lungs were removed on day 2 p.i. and the post-caval lobe (right lung) was taken for histology. One centimetre lengths of the anterior third of the small intestine were collected on day 7 p.i., fixed in $10 \%$ buffered formalin and embedded in paraffin. Five $\mu \mathrm{m}$ sections were cut and stained with $H \& E$ and photographed at $40 \times$ or $100 \times$ magnification. Eosinophils were enumerated in the small intestine by counting 10 complete villus crypt units (VCU)/ section, selected at random, for each of two mice/group.

\subsection{Statistical analysis}

Parasite burdens and inflammatory leukocyte numbers were compared between groups using unpaired Student's $t$-tests in Prism (GraphPad Software Inc.) software, with $P<0.05$ considered significant.

\section{Results}

\subsection{Larval retention and leukocyte recruitment in infected skin}

Nippostrongylus brasiliensis were injected into dorsal air pouches on CBA IL- $5^{-1-}$ and BALB/c $\triangle$ dblGATA mice and on WT and IL-5 Tg mice of the corresponding genetic backgrounds to assess larval retention (Fig. 1) and leukocyte recruitment (Fig. 2) in the skin. Larvae were injected into air pouches on naïve mice and also on animals infected 21 days previously. Most of the larvae inoculated were recoverable by lavage immediately after injection, but $4 \mathrm{~h}$ after primary infection, the majority of larvae $(80-85 \%)$ had escaped from air pouches in WT, IL- $5^{-/-}$and $\Delta \mathrm{dblG}$ ATA mice, with no significant differences in larval numbers between groups (Fig. 1). As shown previously (Daly et al., 1999) there was significant retention of larvae in the skin $4 \mathrm{~h}$ p.i. in primary infections of IL-5 Tg mice (Fig. 1A).

Few leukocytes were recovered by lavage at $0 \mathrm{~h}$ from any group, confirming that there was very little residual or background inflammation resulting from the generation of the air pouches (Fig. 2A and D). However, in both primary and secondary infections, intense inflammatory infiltrates were detected $4 \mathrm{~h}$ p.i. and this was most pronounced in the IL-5 Tg mice. In all groups sampled at $4 \mathrm{~h}$ p.i., neutrophils represented a major component of the cellular infiltrate (Fig. 2B and E). Eosinophils were present in the skin of both WT and IL-5 Tg mice of both genetic backgrounds (Fig. 2C and F), representing approximately 6$17 \%$ and $40-65 \%$ of pouch leukocytes in WT and IL-5 $\mathrm{Tg}$ mice, respectively. Eosinophils were significantly more numerous after secondary infection in WT mice (mean +
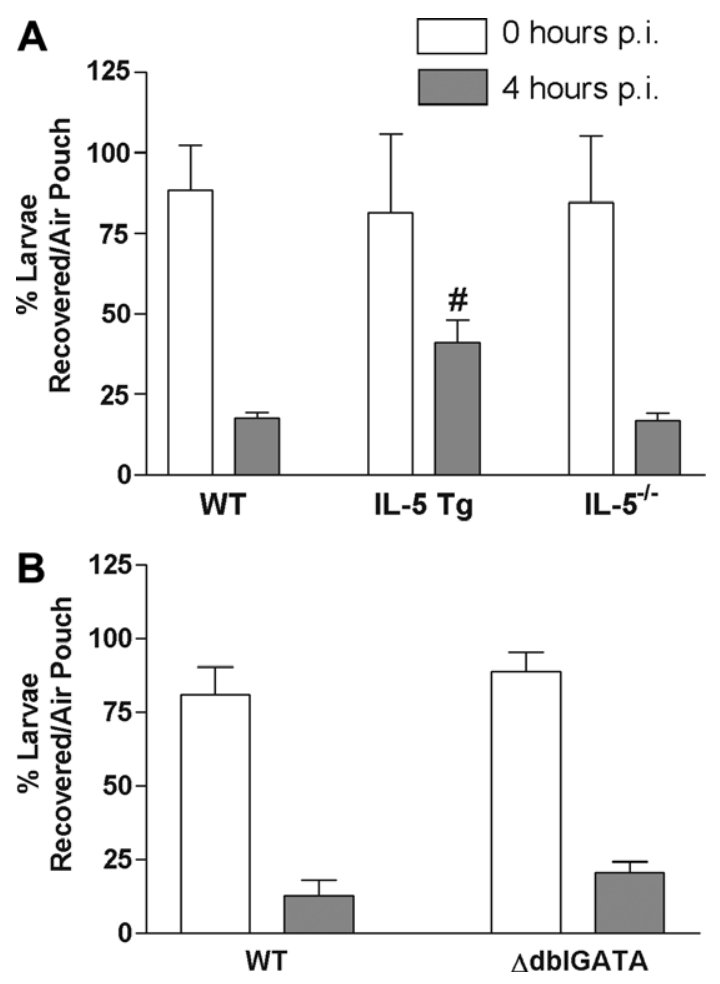

Fig. 1. Larval retention in skin air pouches during primary infections of WT (CBA and BALB/c), IL-5 Tg (CBA), IL- $5^{-1}$ (CBA) and $\triangle$ dblGATA $(\mathrm{BALB} / \mathrm{c})$ mice 0 and $4 \mathrm{~h}$ p.i. Data shown from a single experiment (mean + S.E.M., $n=2$ /group for time 0 and $n=4-5$ /group for $4 \mathrm{~h}$ p.i.), representative of three similar experiments. All $0 \mathrm{~h}$ groups significantly greater than $4 \mathrm{~h}$ group of the same genotype. \#, Significantly greater than WT and IL-5 ${ }^{-1-}$ groups $(4 \mathrm{~h})$. 

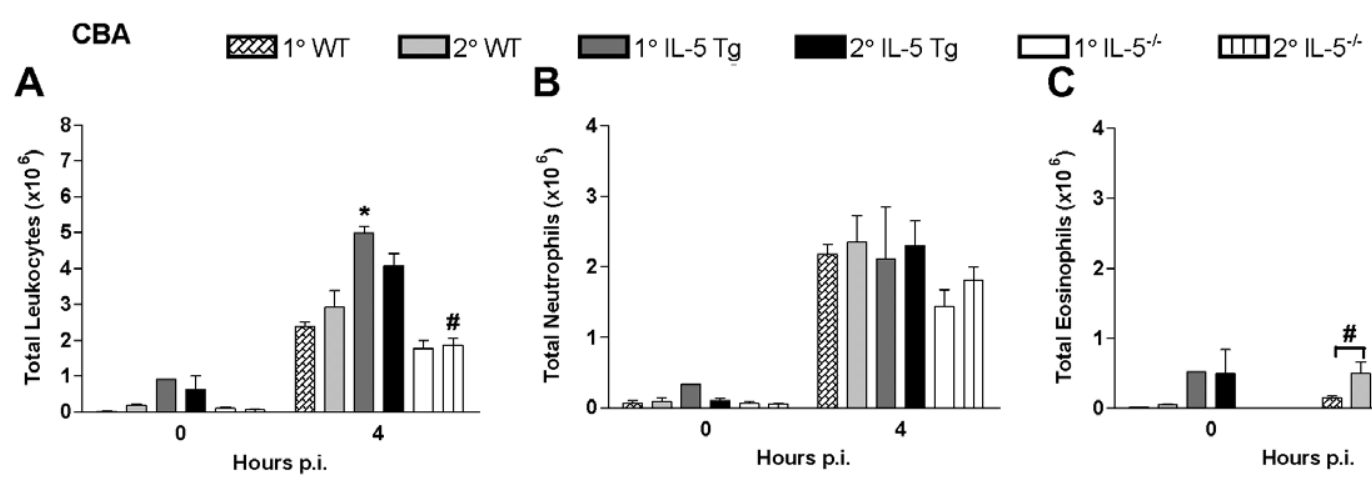

BALB/c
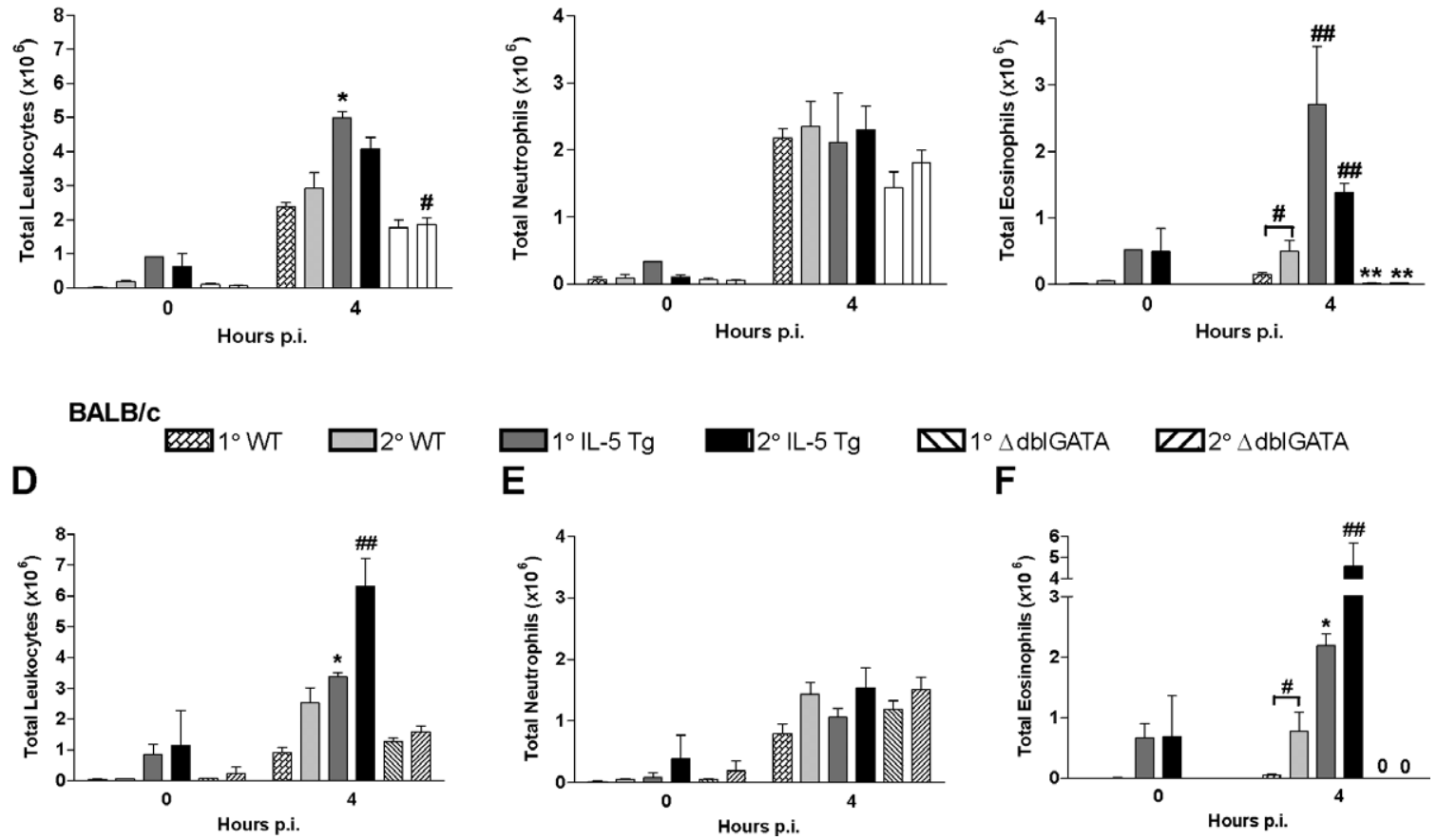

Fig. 2. Total leukocytes (A and D), neutrophils (B and E) and eosinophils (C and F) recovered by lavage of dorsal skin air pouches during primary and secondary Nippostrongylus brasiliensis infections of WT, IL-5 Tg (CBA and BALB/c), IL- $5^{-/}(\mathrm{CBA})$ and $\Delta$ dblGATA (BALB/c) mice 0 and $4 \mathrm{~h}$ p.i. Data represent mean leukocytes + S.E.M., $n=2 /$ group for time 0 and $n=3-5 /$ group for $4 \mathrm{~h}$ p.i. and is representative of three similar experiments. (A) *, Significantly greater than WT primary and IL- $5^{-/-}$primary $(4 \mathrm{~h})$; \#, significantly less than WT secondary and IL-5 Tg secondary $(4 \mathrm{~h})$. (C) **, Significantly less than respective WT $4 \mathrm{~h}$ groups; \#, WT secondary infection significantly greater than primary infection; \#\#, significantly higher than other $4 \mathrm{~h}$ groups. (D and F) *, Significantly greater than all other primary infection groups $(4 \mathrm{~h})$; \#, WT secondary infection significantly greater than primary infection; \#\#, significantly greater than all $4 \mathrm{~h}$ groups. 0 , None detected.

S.E.M., $0.5+0.1 \times 10^{6}$ versus $0.15+0.03 \times 10^{6}$ eosinophils/pouch for secondary versus primary infections, respectively, $P<0.04)$. Very few eosinophils were found at the site of injection in IL-5 $5^{-1-}$ mice and these represented less than $1 \%$ of total leukocytes, regardless of prior infection (Fig. 2C). No eosinophils were seen in samples recovered from $\mathrm{BALB} / \mathrm{c} \triangle \mathrm{dblGATA}$ mice regardless of previous exposure to the larvae (Fig. 2F). Most of the leukocytes recruited in WT and eosinophil-deficient mice were neutrophils and by $4 \mathrm{~h}$ p.i, these cells also represented a major subset in IL-5 Tg mice. Data for lymphocyte and macrophage recruitment are not shown, as they were not numerous in pouch exudates from any mice. Despite greater eosinophil recruitment into skin during secondary infections of WT mice (Fig. 2C and F), few larvae were recovered by needle aspiration $4 \mathrm{~h}$ p.i. (mean + S.E.M. $13+6 \%$ of initial inoculum), and similar numbers were recovered during secondary infections of $\mathrm{IL}^{-5^{-1}}$ or $\Delta$ dblGATA mice (mean + S.E.M. $15+3 \%$ and $28+7 \%$ of initial inoculum, respectively). Similar results were found in three replicate experiments.

\subsection{Lung larval recovery and inflammation}

The number of larvae found in the lungs $24-48 \mathrm{~h}$ p.i. is a good indicator of anti-parasite resistance in the pre-lung stage of infections (Daly, 1999; Dent et al., 1999). As expected in primary infections, IL-5 Tg mice had fewer larvae in the lungs than any other group (Fig. 3). In contrast, there were no significant differences in the number of larvae recovered from WT and IL-5 ${ }^{-/-}$(Fig. 3A, B) and WT and $\triangle$ dblGATA (Fig. 3C) mice during primary infections. Few larvae were found in the lungs of CBA or BALB/c WT and IL-5 Tg mice during secondary infections, whereas eosinophil-deficient IL-5 ${ }^{-/-}$and $\Delta$ dblGATA mice displayed impaired resistance to secondary infection, with significantly more lung larvae than re-challenged WT mice (Fig. 3). This novel and important finding strongly suggests that IL-5 and/or eosinophils are important for early resistance to secondary infection with $N$. brasiliensis.

Although in primary infections strong inflammatory leukocyte infiltrates are seen in the lungs of mice six or more days p.i. (Coyle et al., 1998; Daly, 1999), few leukocytes were recruited during the period when larvae were actually present in the lungs (e.g. $48 \mathrm{~h}$ p.i., Fig. 4) and this is in marked contrast to the rapid and extensive recruitment of leukocytes seen within $4 \mathrm{~h}$ of infection of the skin (Fig. 2). In primary infections, some eosinophils were present in the lungs of all but the $\Delta$ dblGATA mice, but were not particularly numerous even in IL-5 Tg mice and were not localized around larvae. Some macrophages were present, but were also not in close proximity to the 

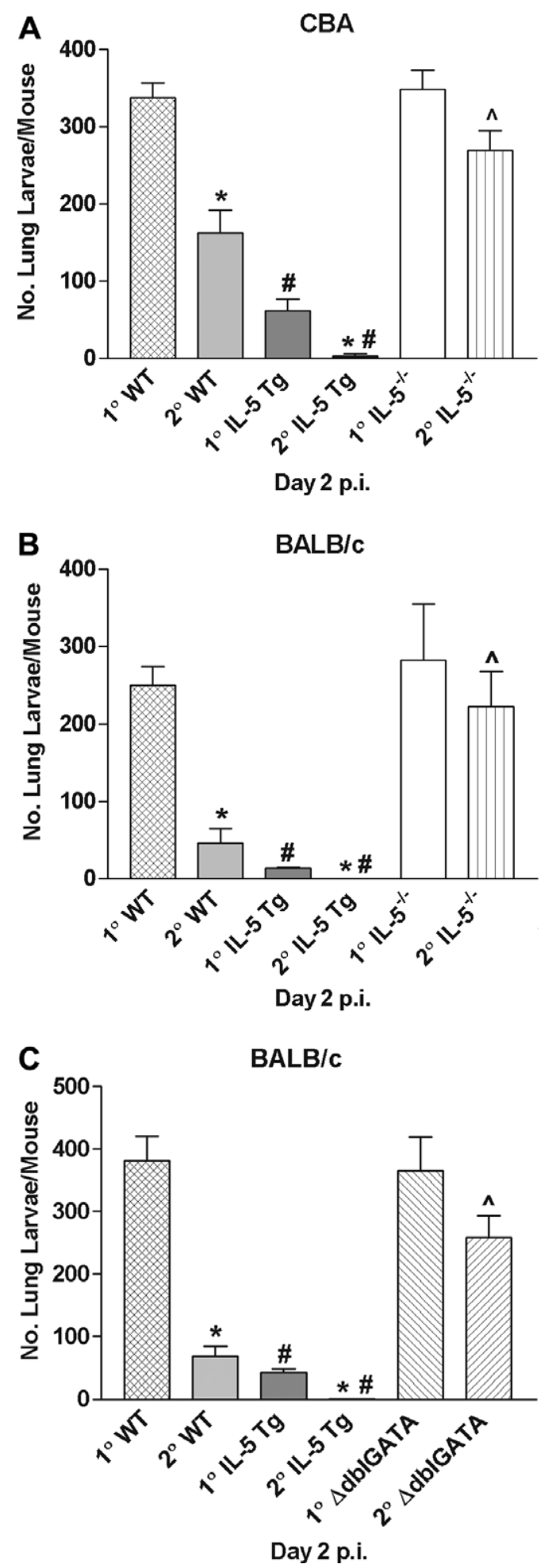

Fig. 3. Lung larval recovery day 2 p.i. of (A) CBA and (B) BALB/c WT, IL$5 \mathrm{Tg}$ and $\mathrm{IL}-5^{-/-}$and (C) BALB/c WT, IL-5 Tg and $\Delta$ dblGATA mice after primary or secondary infection with Nippostrongylus brasiliensis. Data represents mean lung larval burden/mouse + S.E.M. Data for CBA mice combined from up to eight separate experiments, $n=24-33 /$ group for WT and IL- $5^{-/}$groups, $n=12-13$ for IL-5 Tg group. Data for BALB/c mice from one experiment ( $n=3-4$ mice/group), representative of two similar experiments. *, Significantly less than primary infection group of the same genotype. \#, Primary and secondary IL-5 Tg significantly less than corresponding WT and IL- $5^{-/-}$or $\Delta$ dblGATA groups. $\wedge, \mathrm{IL}-5^{-/-}$and $\Delta$ dblGATA secondary significantly greater than WT secondary groups. larvae (Fig. 4). Surprisingly, lungs from animals undergoing secondary infection were also not particularly rich in leukocytes by day 2 p.i. and were not substantially different to the lungs of mice exposed to parasites for the first time. This suggests that neither eosinophils nor other leukocytes are acting within the lungs to trap or kill larvae and that eosinophil-dependent killing in primary and secondary infections occurs prior to the lung stage.

\subsection{Intestinal phase of infection}

In WT mice, larvae typically begin arriving in the intestine around days $2-3$ p.i. and mature to produce eggs from days 5-8, with peak production occurring at day 6 and worm expulsion by day 9 (Kassai, 1982; Dent et al., 1999). Lung larval numbers had declined by day 3 in both primary and secondary infections (mean + S.E.M. for day 2 versus day 3 of secondary infections: WT versus IL-5 $5^{-1-}$; WT, $223+36($ day 2$)$ and $62+5$ (day 3$)$ versus IL-5 $5^{-1-}$, $270+28$ (day 2) and $42+5$ (day 3 ); and for WT versus $\triangle$ dblGATA, WT; $69+16$ (day 2) and $3+1$ (day 3 ) versus $\Delta$ dblGATA, $259+34$ (day 2) and $4+2$ (day 3)), suggesting that larvae had begun migrating to the gut. Intestinal parasite burdens were assessed at day 3 and/or 7 p.i. (Fig. 5A, B) and egg production on day 6 p.i. (Fig. 5C, D) in WT and IL-5 Tg mice (CBA and BALB/c strains) and in CBA IL-5 ${ }^{-1-}$ and BALB/c $\Delta$ dblGATA mice. While some larvae did migrate to the gut in secondary infections of CBA WT mice 3 days p.i., numbers recovered were significantly less than in primary infected animals (Fig. 5A). In contrast, IL- $5^{-1-}$ mice had comparable numbers of worms at day 3 p.i. of primary and secondary infections. Similar results were found at day 3 of a secondary infection of $\Delta$ dblGATA mice (mean + S.E.M. intestinal larvae: WT, $9+4$ versus $\Delta$ dblGATA $27+9$ ). Significantly higher numbers of eggs were found in eosinophil-deficient mice than in their WT counterparts during primary infections (Fig. 5C, D). However, during primary infections of IL-5 Tg mice and secondary infections of WT, IL-5 Tg, IL- $5^{-1-}$ and $\triangle$ dblGATA mice, few or no worms were present in the intestine on day 7 p.i. (Fig. 5A, B) and those that were, produced few or no eggs (Fig. 5C, D).

Histological analysis of the small intestine showed eosinophils were present in the lamina propria and submucosa of the small intestine during both primary and secondary $N$. brasiliensis infections of WT and IL-5 Tg mice (Fig. 6). Significantly more eosinophils were seen in IL-5 Tg than in WT mice (Fig. 7). Although eosinophils were detected in the gut in IL-5 $5^{-/-}$animals during both primary and secondary infections, there were significantly less than in the WT counterparts. No eosinophils were detected in $\triangle$ dblGATA mice (Figs. 6G, $\mathrm{H}$ and 7). Relative to the same time point in primary infections (day 7 p.i.), eosinophil numbers in the small intestine were not significantly elevated in secondary infections within any line or strain. 

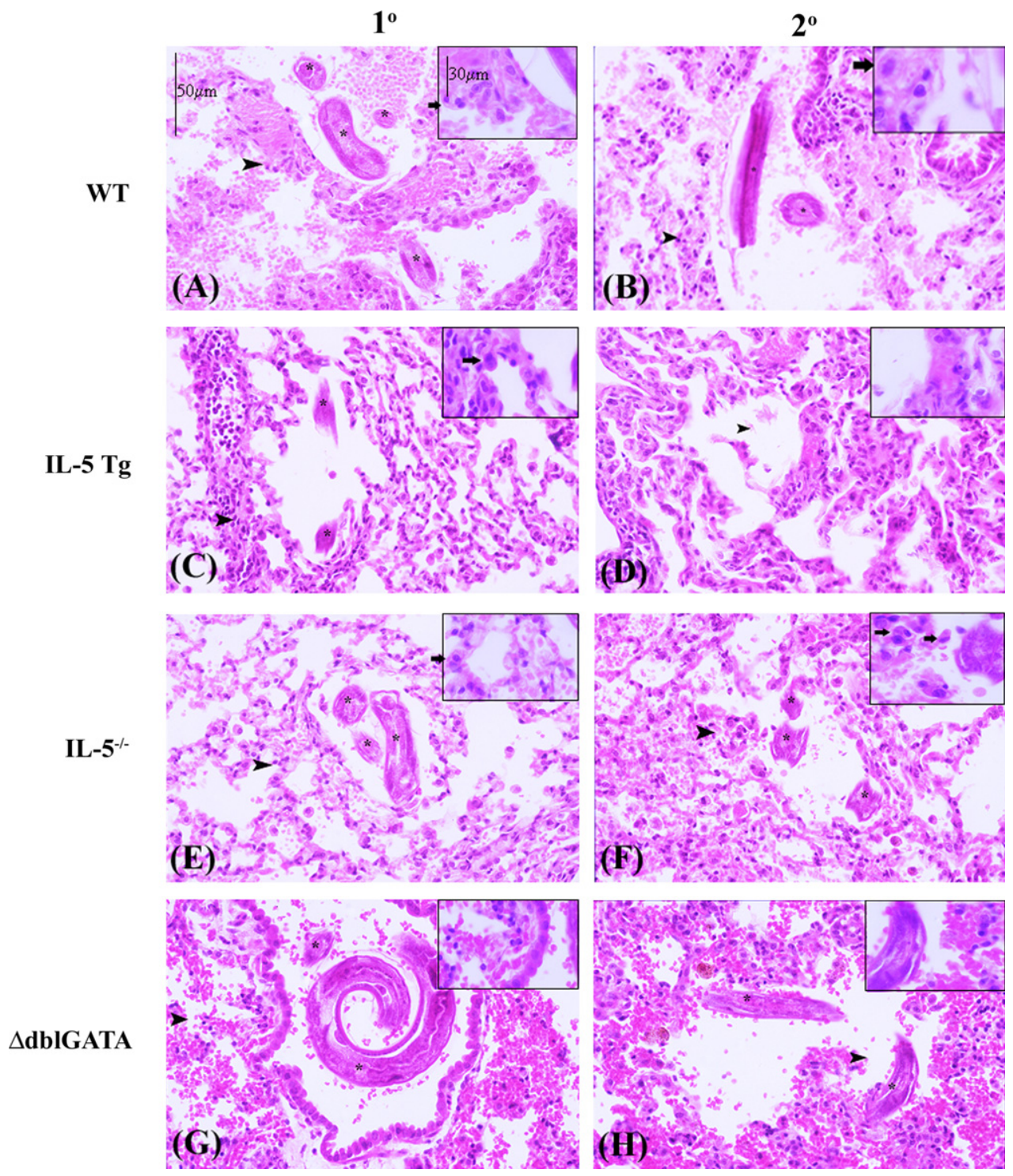

Fig. 4. Day 2 p.i. lung histology for primary (A, C, E, G) and secondary (B, D, F, H) infections of CBA WT (A, B), IL-5 Tg (C, D), IL-5 ${ }^{-/-}$(E, F) and

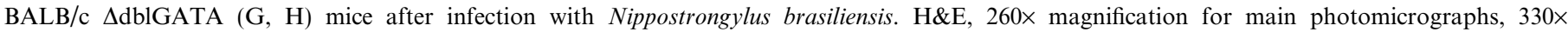
magnification for insets. *, Lung larvae. $>$, Area shown in inset. $\rightarrow$, Macrophage.

\section{Discussion}

In this study we have compared WT mice with IL-5 $5^{-/-}$ and $\triangle$ dblGATA mice to establish that there are relatively short periods within late primary and early secondary $N$. brasiliensis infections when eosinophils are likely to make especially important contributions. This is consistent with our previous observations in IL-5 $\mathrm{Tg}$ mice, in which we showed that eosinophils provide protection against primary $N$. brasiliensis infections (Dent et al., 1997b; Daly et al., 1999, 2004). The parasite is likely to be most vulnerable to attack by eosinophils shortly after entering the skin, or at least in the pre-lung phase of the infection. In naïve WT laboratory animals, eosinophils are generally not available in sufficient numbers to be attracted en masse to the skin and as expected, the IL- $5^{-1-}$ and $\Delta$ dblGATA mutations had no impact on the rate of migration of $N$. brasiliensis to the lungs during primary infections. However, during secondary infections, IL- $5^{-/-}$and the $\Delta \mathrm{dblG}$ ATA mice were more susceptible than WT animals at the pre-lung stage. Nippostrongylus brasiliensis larvae seem to be unharmed by the neutrophils that were recruited in relative abundance in primary infections in all of the hosts tested. Eosinophil-dependent resistance established in the skin within just a few hours of exposure to the parasite did not extend to the lungs $48 \mathrm{~h}$ later, where relatively few leukocytes of any kind were detected during either primary or secondary infections. Eosinophils may also play a role in the later stages of primary $N$. brasiliensis infection in the gut, as there was a significant enhancement in adult worm burden and/or egg production in eosinophil-deficient IL-5 $5^{-/-}$and $\Delta$ dblGATA mice compared with WT animals. 

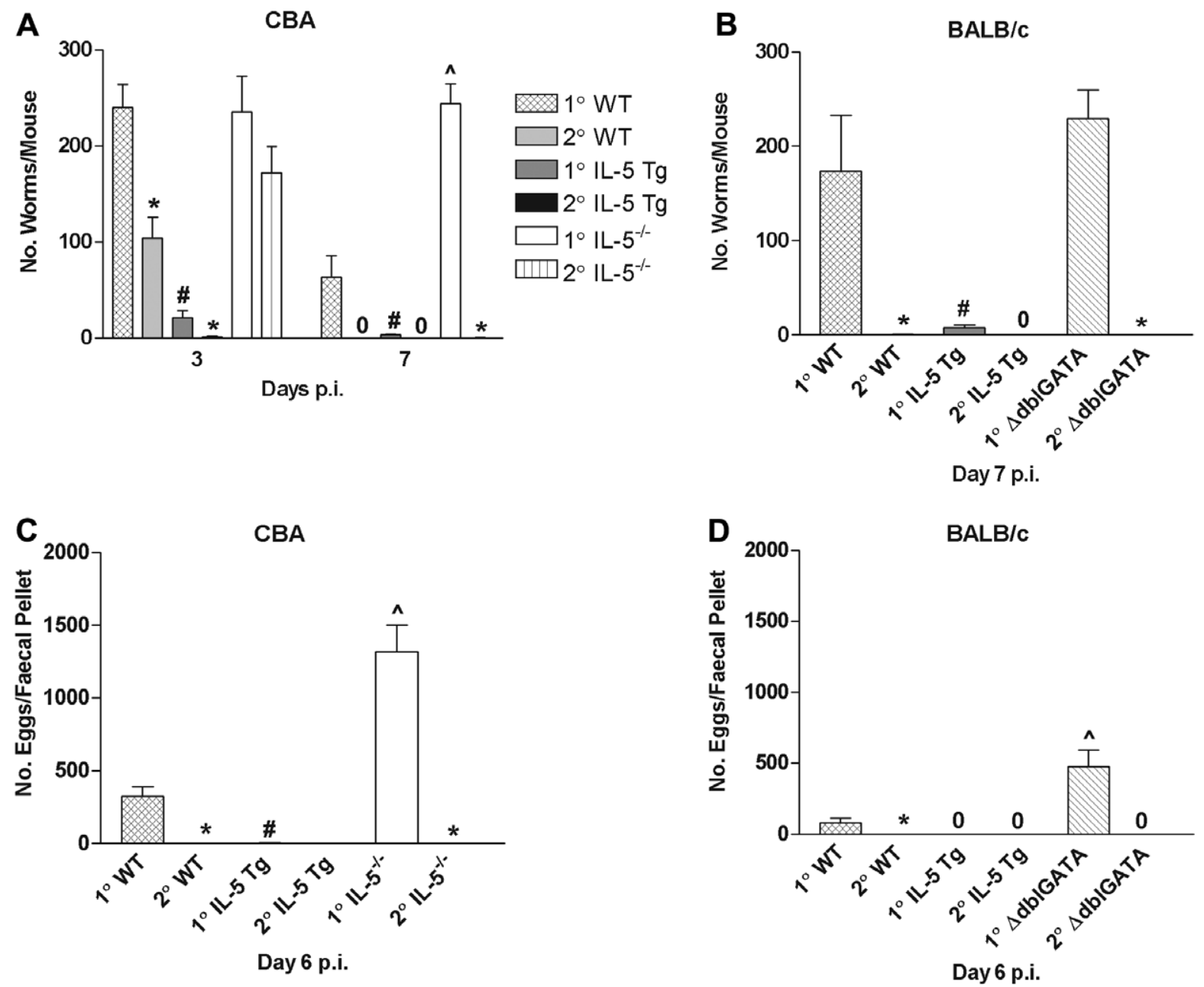

Fig. 5. Day 7 intestinal worm counts (A, B) and day 6 parasite faecal egg production (C, D) during primary and secondary Nippostrongylus brasiliensis infections of WT, IL-5 Tg (CBA and BALB/c), IL-5 ${ }^{-/}$(CBA) and $\Delta$ dblGATA (BALB/c) mice. (A, B, D) Data represent mean + S.E.M., $n=4-8 /$ group from a single representative experiment, repeated three times with similar results. (C) Data combined from up to eight separate experiments, mean + S.E.M., $n=22-30 /$ group for WT and IL- $5^{-/-}$groups, $n=6$ for IL-5 Tg group. *, Significantly less than primary infection of the same genotype. \#, IL-5 Tg significantly less than other primary infection groups. $\wedge$, Primary IL- $5^{-/-}$or $\Delta$ dblGATA group significantly greater than primary WT group. 0 , None detected.

However, our data also confirm that if eosinophils and/or IL-5 do contribute to the expulsion of intestinal worms, other mechanisms readily and adequately compensate for the absence of these cells in both primary and secondary infections.

In their seminal study of $N$. brasiliensis (previously known as Nippostrongylus muris) infections in rats, Taliaferro and Sarles (1939) showed that leukocytes are recruited to the skin during the first $24 \mathrm{~h}$ after reinfection and that larvae may be trapped within inflammatory nodules at both this site and in the lungs. These workers found eosinophils in skin nodules within the first $24 \mathrm{~h}$ after reinfection, but noted that recruitment of these cells was extensive by day 3 p.i. (Taliaferro and Sarles, 1939). The current study and our earlier work suggest that if eosinophils are available in sufficient numbers, larvae can be trapped either in the skin, or at least in the pre-lung phase of infection. Importantly, in the present study we have demonstrated that eosinophils contribute to protection against secondary infections with $N$. brasiliensis and we have done so in models that do not rely upon IL-5 transgene-driven constitutive eosinophilia.

Although IL-5 is a major growth, differentiation and survival factor for eosinophils in vivo (Yamaguchi et al., 1998; Dent et al., 1990; Sanderson, 1990; Vaux et al., 1990), cytokines such as IL-3 and granulocyte-macrophage colony-stimulating factor (GM-CSF) also contribute (Sanderson, 1992), as can be seen in IL- $5^{-1-}$ mice, which have low basal levels of eosinophils of normal morphology (Sanderson, 1992; Kopf et al., 1996). We have shown that as $N$. brasiliensis passes through the skin and gut in infected IL$5^{-1-}$ mice, eosinophils are recruited in very small numbers. However, eosinophil recruitment in these animals is not enhanced on secondary exposure to the parasite. $\Delta$ dblGATA mice are unable to produce eosinophils due to deletion of a high-affinity GATA-binding site in the GATA-1 promoter ( $\mathrm{Yu}$ et al., 2002) and show less airway remodelling than WT mice in an experimental model of allergic 
$1^{\circ}$

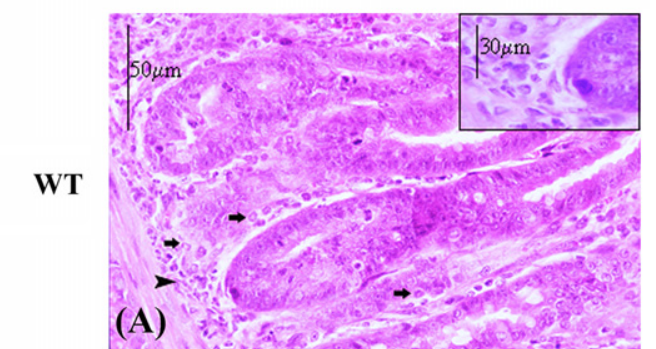

(A)
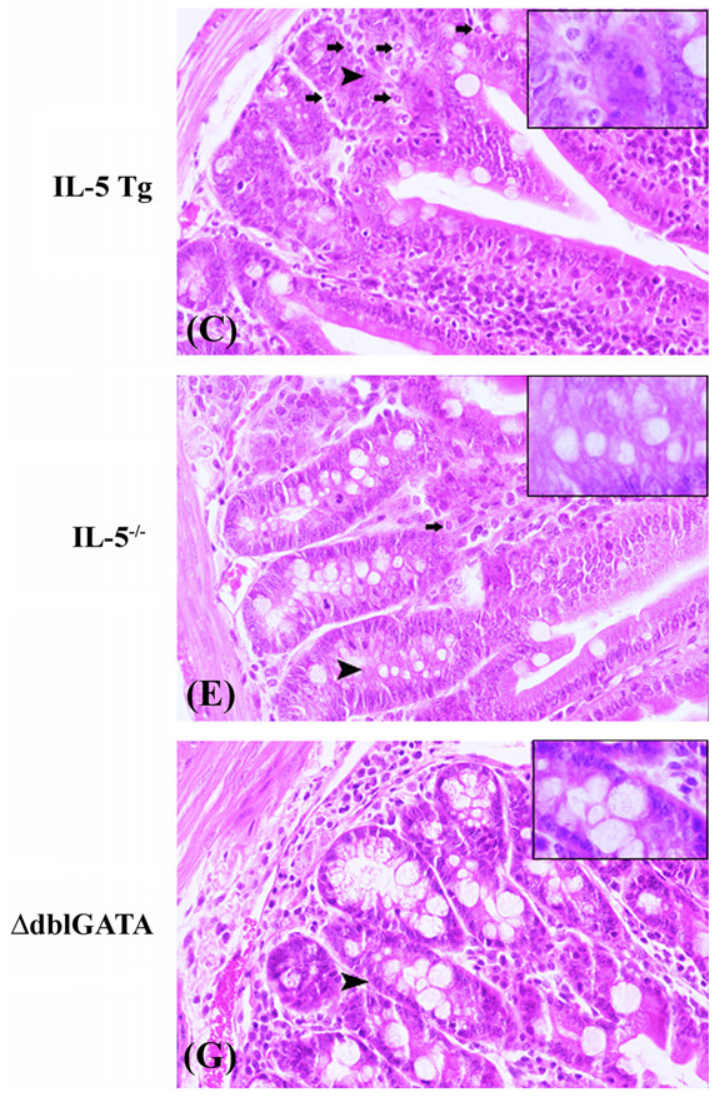
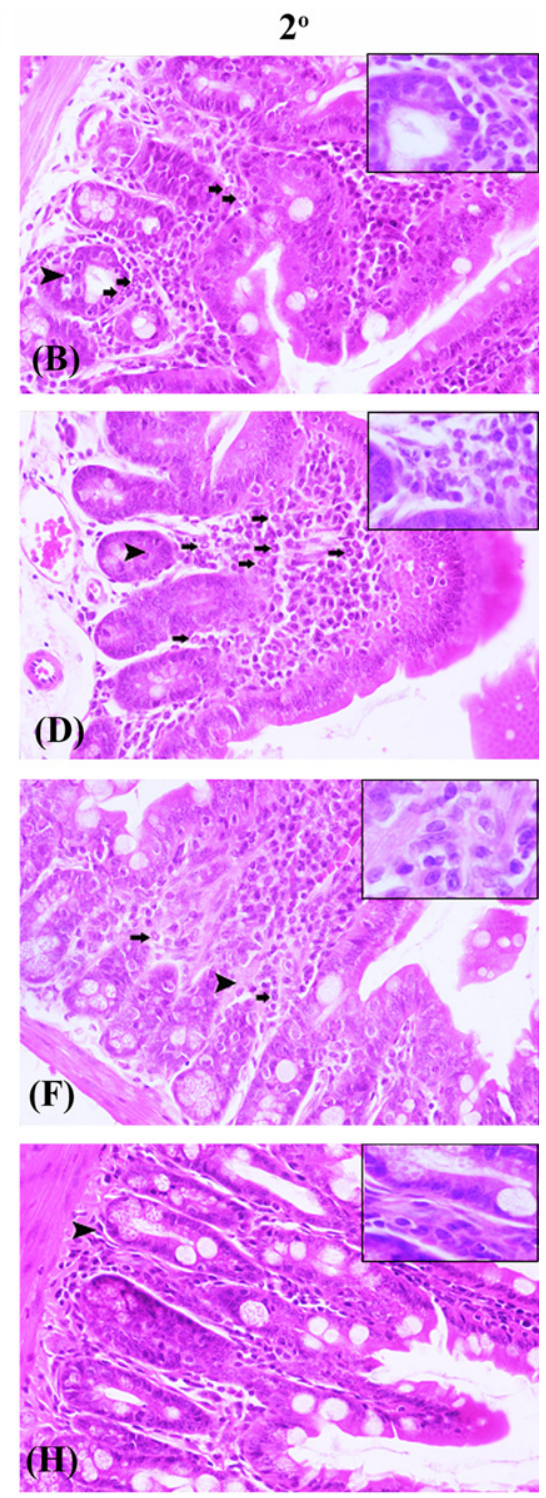

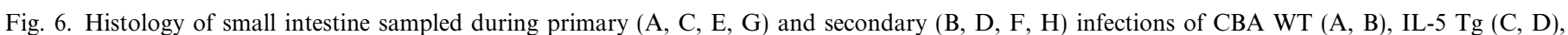

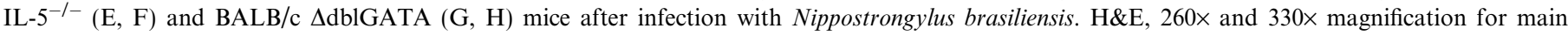
photomicrographs and insets, respectively. $>$, Area shown in inset. $\rightarrow$, Eosinophil.

asthma (Humbles et al., 2004). In the current study we have also found no evidence of eosinophil recruitment in response to either primary or secondary $N$. brasiliensis infections in $\triangle \mathrm{dblGATA}$ mice. Other GATA-1-expressing haematopoietic lineages are either unaffected (megakaryocytes, platelets and mast cells) or in the case of erythrocytes, only minimally so in these mice ( $\mathrm{Yu}$ et al., 2002) and we have also found no additional abnormalities.

IL-5 Tg mice were not the main focus of this study, but some interesting observations were made that deserve comment. For example, we would expect to see more eosinophils recruited into the skin in a secondary infection relative to a primary infection and this was found in both CBA and BALB/c WT mice and in IL-5 Tg BALB/c mice, but curiously, not in the IL-5 Tg CBA mice. This may be due to a combination of the effects of strain differences on eosinophil recruitment and the consequences of IL-5 Tg expression. Mechanisms regulating eosinophil recruitment and survival may be stronger in CBA than BALB/c mice. Eosinophils are found in larger numbers in the lungs of both $\mathrm{BALB} / \mathrm{c}$ and $\mathrm{C} 57 \mathrm{BL} / 6$ mice allergic to ovalbumin, than in similarly treated CBA mice and this may be due to enhanced eosinophil apoptosis in the latter (Tumes et al., 2007). It is also worth noting that we can only accurately count leukocytes recruited, but not attached to, larvae. It may be that relative to primary infections, more leukocytes are recruited to the skin in secondary challenges of CBA IL-5 Tg mice, but these cells may also be more efficiently sequestered onto larvae. Although this should also happen in secondary infections of $\mathrm{BALB} / \mathrm{c}$ mice, there may be an excess of eosinophils recruited in this strain.

This and our earlier studies demonstrate that leukocytes are recruited into the skin in large numbers within the first hour of infection and this peaks at approximately $4 \mathrm{~h}$ p.i. 

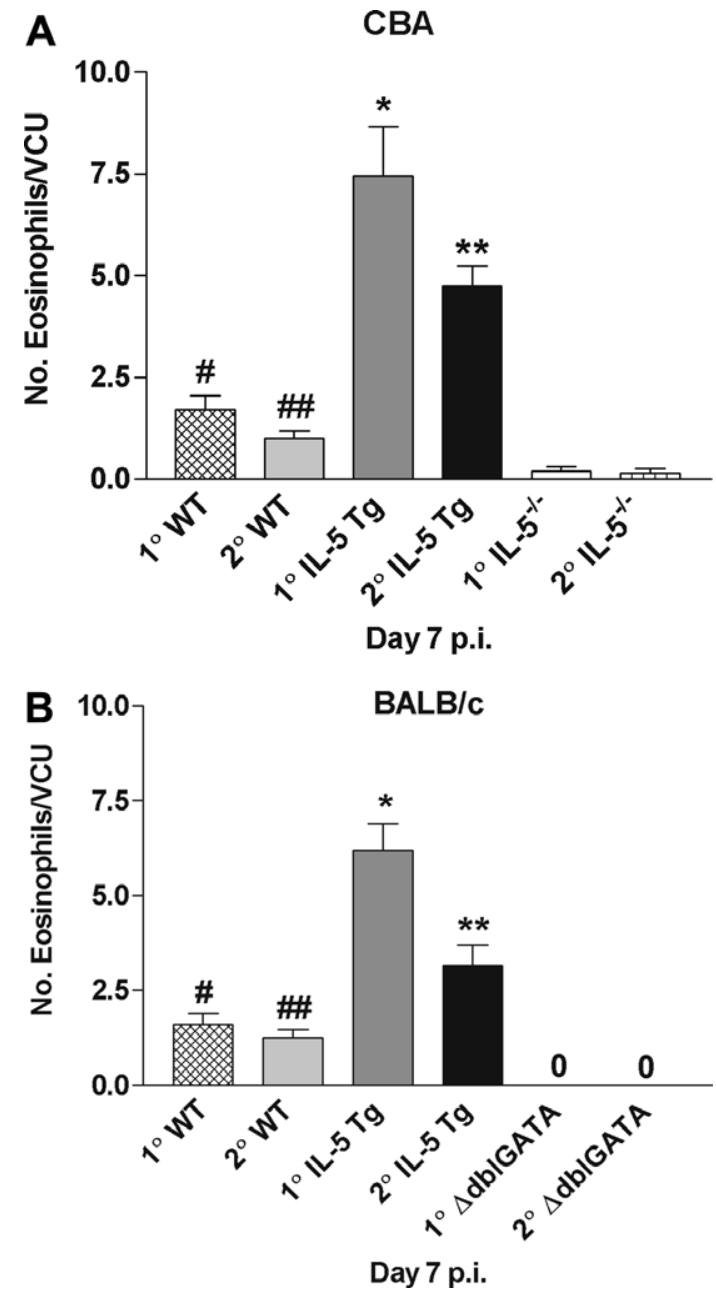

Fig. 7. Mean number of eosinophils/villus crypt unit (VCU) + S.E.M. in sections of small intestine sampled on day 7 p.i. of primary and secondary Nippostrongylus brasiliensis infections in WT, IL-5 Tg (CBA and BALB/ c), IL-5 ${ }^{-1-}$ (CBA) and $\triangle$ dblGATA mice (BALB/c) mice. *, IL-5 Tg primary significantly greater than other primary infection groups. \#, WT primary significantly greater than $\mathrm{IL}-5^{-/-}$or $\Delta$ dblGATA primary groups. **, IL-5 Tg secondary significantly greater than other secondary infection groups. \#\#, WT secondary significantly greater than IL- $5^{-/-}$or $\Delta \mathrm{dblG-}$ ATA secondary groups. 0 , None detected.

(Daly et al., 1999). In contrast, in both primary and secondary infections, very few leukocytes are seen in the lungs during the period ( $24-48 \mathrm{~h}$ p.i.) in which most of the larvae are present. Attachment of eosinophils to the parasite is largely dependent on complement activated via the alternative pathway (Giacomin et al., 2005). Complement activation may also be important for eosinophil recruitment to the skin via generation of the eosinophil chemoattractants $\mathrm{C} 3 \mathrm{a}$ and C5a. However by the lung stage of a primary infection, larvae no longer bind complement and eosinophils do not appear to be recruited and/or fail to recognize larvae at this site (Daly et al., 1999; Giacomin et al., 2005). Helminths may be capable of minimizing inflammation during passage through tissues such as the lungs (Yazdanbakhsh et al., 2001; Maizels et al., 2004), allowing both the parasite and the host to survive. However, in a recent study using microarray analysis, there was no large-scale downregulation of innate pro-inflammatory mechanisms in the lungs during the first few days of $N$. brasiliensis infection (Reece et al., 2006). Nevertheless, the relative lack of inflammation in the lungs in the first $48 \mathrm{~h}$ of infection is especially noteworthy because on entry into the parenchyma, larvae cause extensive focal haemorrhaging. A more substantial late inflammatory response is seen in the lungs during primary infections of WT rats (Taliaferro and Sarles, 1939; McNeil et al., 2002) and mice (Daly, 1999; Shinkai et al., 2002), but it is worth noting that this also does not occur until several days after most larvae have left this tissue (Daly et al., 1999). Many leukocytes, including lymphocytes, are recruited at this later stage, but since the parasite is no longer present and may even have completed its life cycle, the value of this response to the host may be largely limited to priming for secondary and subsequent infections.

IL-4 and IL-13 are variously considered to be the most important cytokines for expulsion of worms from the gut but IL-5, IL-9 and IL-25 may also make contributions (Urban et al., 1998; Daly, 1999; Fallon et al., 2002, 2006; Zhao et al., 2003). Anti-IL-5 antibody treatment profoundly reduces blood and/or pulmonary eosinophilia in primary $N$. brasiliensis infections in WT mice (Coffman et al., 1989; Kopf et al., 1996), however we and others have not found this to be associated with increased migration of larvae in primary infections of WT mice (Khan et al., 1995; Daly et al., 2004). Surprisingly, the effects of deletion of the IL-5 gene alone on the intestinal phase of $N$. brasiliensis infections have not previously been reported. Fallon et al. (2002) described increased $N$. brasiliensis worm burdens and/or delayed rates of clearance during primary infections of IL-5 $5^{-/-}$mice of mixed genetic background, but only in combination with deletions of genes encoding two or more of the other Type 2 cytokines. Under normal circumstances, eosinophils are present in substantial numbers in the lamina propria of the small intestine and significantly more are found during and after the intestinal phase of primary $N$. brasiliensis infections (Dent et al., 1999). In the present study, we found no obvious increase in the numbers of intestinal eosinophils on rechallenge. Indeed, in both CBA and BALB/c IL-5 Tg mice, we reproducibly found less eosinophils in the intestinal epithelium during secondary infections and this may be due to the difficulty of detecting degranulated eosinophils histologically. However, it is more likely that larvae are either trapped prior to entry into the gut or expelled more readily and so there may be less potent stimulation of eosinophil recruitment to the gut.

It is not clear how eosinophils or IL-5 might contribute to anti-parasite immunity in the gut, but this may be via broader physiological responses, including changes to the epithelium (Madden et al., 2004), mucus secretion (Khan et al., 1995) and smooth muscle contractility (Zhao et al., 2003). Larvae that reach the gut of IL-5 Tg mice during a primary infection fail to grow, do not readily localize 
to the preferred anterior end of the small intestine and do not produce eggs (Dent et al., 1999). This may be due in large part to damage incurred in transit to the small intestine, but further damage or impairment of development may occur after arrival in the gut. The present study suggests that in primary infections of CBA $\mathrm{IL}-5^{-1-}$ and $\mathrm{BALB} / \mathrm{c} \Delta \mathrm{dblGATA}$ mice, disruption of eosinophilopoiesis may be associated with relatively modest increases in intestinal worm and/or egg loads. More significantly, by day 3 of secondary infections of WT mice, intestinal larval numbers were substantially lower than in primary infections, but this enhanced resistance was not seen in $\mathrm{IL}-5^{-/}$or $\Delta$ dblGATA mice. Nevertheless, by day 7 of secondary infections, almost no worms or eggs were detected in WT, IL- $5^{-/-}$or $\triangle$ dblGATA mice. The impairment of eosinophilopoiesis does adversely affect the early stage of resistance in a secondary response and this would allow more larvae to take up residence in the gut. However, IL5 and eosinophil-independent mechanisms completely compensate for this over days 4-7 p.i., leading to nearcomplete worm expulsion.

Some authors have expressed doubt about the importance of eosinophils in resistance to parasitic helminths (Lee, 1991; Behm and Ovington, 2000; Meeusen and Balic, 2000; Lee and Lee, 2005), but there is a mounting body of evidence suggesting that these cells contribute to protection against at least some species. IL-5 deficiency achieved by either anti-IL-5 antibody treatment or gene disruption, has been associated with increased susceptibility to Strongyloides ratti (Ovington et al., 1998), Strongyloides venezuelensis (Korenaga et al., 1991), Angiostrongylus cantonensis (Sasaki et al., 1993), Trichinella spiralis (Vallance et al., 2000) and Brugia pahangi (Ramalingam et al., 2003), but not to Mesocestoides corti (Kopf et al., 1996) or Toxocara canis (Takamoto et al., 1997). Over-expression of IL-5 confers protection against $N$. brasiliensis (Dent et al., 1997b, 1999) and S. ratti (Dent et al., unpublished data), but not to $M$. corti (Strath et al., 1992) or T. canis (Sugane et al., 1996; Dent et al., 1999) and is actually associated with increased parasite burdens in primary Schistosoma mansoni (Dent et al., 1997a) and T. spiralis (Dent et al., 1997b) infections. It is therefore not possible to generalize about the value or otherwise, of eosinophils in immunity to a wide range of tissue-invasive helminth species and caution must also be exercised when extrapolating to other host species. Humans infected with tissue-invasive parasitic helminths often have blood and tissue eosinophilia, however the value of such a response is poorly understood (Klion and Nutman, 2004). Our own studies have demonstrated that a beneficial role for eosinophils may not be evident without close scrutiny of all phases of infection. This clearly applies to $N$. brasiliensis, a useful experimental model for aspects of hookworm and Strongyloides stercoralis infections in humans and this study justifies further examination of the kinetics of infections for other parasite species. Although some parasite species may have life stages that are highly resistant to killing by eosinophils and indeed may reside without damage in granulomas rich in these cells, the same parasites may be very susceptible to eosinophil-mediated killing at other points in the life cycle. Obviously there is value in determining when parasites are most vulnerable and what makes them more resistant to eosinophils and other effector cells. Understanding that eosinophils can protect against some tissue-invasive parasites as they enter the host through the skin, may be of key importance for the development of both therapeutic and vaccine strategies.

\section{Acknowledgements}

We thank Dr. Stuart Orkin for providing the $\Delta$ dblGATA mice and Dr. Craig Gerard for the breeding stock. Thanks also to Wayne Damcevski for assistance with animal production. This work was supported in part by the Australian Government National Health and Medical Research Council Project (L.D.) and Program (K.M. and P.F.) grants and the University of Adelaide (L.D.).

\section{References}

Ackerman, S.J., Kephart, G.M., Francis, H., Awadzi, K., Gleich, G.J., Ottesen, E.A., 1990. Eosinophil degranulation. An immunologic determinant in the pathogenesis of the Mazzotti reaction in human onchocerciasis. J. Immunol. 144, 3961-3969.

Behm, C.A., Ovington, K.S., 2000. The role of eosinophils in parasitic helminth infections: insights from genetically modified mice. Parasitol. Today 16, 202-209.

Chan, M.S., Medley, G.F., Jamison, D., Bundy, D.A., 1994. The evaluation of potential global morbidity attributable to intestinal nematode infections. Parasitology 109, 373-387.

Coffman, R.L., Seymour, B.W.P., Hudak, S., Jackson, J., Rennick, D., 1989. Antibody to interleukin-5 inhibits helminth-induced eosinophilia in mice. Science 245, 308-310.

Coyle, A.J., Kohler, G., Tsuyuki, S., Brombacher, F., Kopf, M., 1998. Eosinophils are not required to induce airway hyperresponsiveness after nematode infection. Eur. J. Immunol. 28, 2640-2647.

Daly, C.M., 1999. Immune responses to Nippostrongylus brasiliensis in interleukin-5 transgenic mice. $\mathrm{PhD}$, The University of Adelaide, Adelaide.

Daly, C.M., Mayrhofer, G., Dent, L.A., 1999. Trapping and immobilization of Nippostrongylus brasiliensis larvae at the site of inoculation in primary infections of interleukin-5 transgenic mice. Infect. Immun. 67, 5315-5323.

Daly et al., 2004. Eosinophils as mediators of early resistance in mice to the nematode Nippostrongylus brasiliensis. 12th International Congress of Immunology, vol. 27(4), 99D, Clinical Experimental Medicine, Montreal, Canada, pp.133.

Dent, L.A., 2002. For better or worse: common determinants influencing health and disease in parasitic infections, asthma and reproductive biology. J. Reprod. Immunol. 57, 255.

Dent, L.A., Strath, M., Mellor, A.L., Sanderson, C.J., 1990. Eosinophilia in transgenic mice expressing interleukin 5. J. Exp. Med. 172, 14251431.

Dent, L.A., Munro, G.H., Piper, K.P., Sanderson, C.J., Finlay, D.A., Dempster, R.K., Bignold, L.P., Harkin, D.G., Hagan, P., 1997a. Eosinophilic interleukin 5 (IL-5) transgenic mice: eosinophil activity and impaired clearance of Schistosoma mansoni. Parasite Immunol. 19, 291-300.

Dent, L.A., Daly, C., Geddes, A., Cormie, J., Finlay, D.A., Bignold, L., Hagan, P., Parkhouse, R.M., Garate, T., Parsons, J., Mayrhofer, G., 
1997b. Immune responses of IL-5 transgenic mice to parasites and aeroallergens. Mem. Inst. Oswaldo Cruz 92, 45-54.

Dent, L.A., Daly, C.M., Mayrhofer, G., Zimmerman, T., Hallett, A., Bignold, L.P., Creaney, J., Parsons, J.C., 1999. Interleukin-5 transgenic mice show enhanced resistance to primary infections with Nippostrongylus brasiliensis but not primary infections with Toxocara canis. Infect. Immun. 67, 989-993.

Desakorn, V., Suntharasamai, P., Pukrittayakamee, S., Migasena, S., Bunnag, D., 1987. Adherence of human eosinophils to infective filariform larvae of Necator americanus in vitro. Southeast Asian J. Trop. Med. Public Health 18, 66-72.

Egwang, T.G., Gauldie, J., Befus, D., 1984. Broncho-alveolar leucocyte responses during primary and secondary Nippostrongylus brasiliensis infection in the rat. Parasite Immunol. 6, 191-201.

Fallon, P.G., Jolin, H.E., Smith, P., Emson, C.L., Townsend, M.J., Fallon, R., McKenzie, A.N., 2002. IL-4 induces characteristic Th2 responses even in the combined absence of IL-5, IL-9, and IL-13. Immunity $17,7-17$.

Fallon, P.G., Ballantyne, S.J., Mangan, N.E., Barlow, J.L., Dasvarma, A., Hewett, D.R., McIlgorm, A., Jolin, H.E., McKenzie, A.N., 2006. Identification of an interleukin (IL)-25-dependent cell population that provides IL-4, IL-5, and IL-13 at the onset of helminth expulsion. J. Exp. Med. 203, 1105-1116.

Finkelman, F.D., Madden, K.B., Cheever, A.W., Katona, I.M., Morris, S.C., Gately, M.K., Hubbard, B.R., Gause, W.C., Urban Jr., J.F., 1994. Effects of interleukin 12 on immune responses and host protection in mice infected with intestinal nematode parasites. J. Exp. Med. 179, 1563-1572.

Foster, P.S., Hogan, S.P., Ramsay, A.J., Matthaei, K.I., Young, I.G., 1996. Interleukin 5 deficiency abolishes eosinophilia, airways hyperreactivity, and lung damage in a mouse asthma model. J. Exp. Med. 183, 195-201.

Giacomin, P.R., Wang, H., Gordon, D.L., Botto, M., Dent, L.A., 2005. Loss of complement activation and leukocyte adherence as Nippostrongylus brasiliensis develops within the murine host. Infect. Immun. 73, 7442-7449.

Glauert, A.M., Butterworth, A.E., Sturrock, R.F., Houba, V., 1978. The mechanism of antibody-dependent, eosinophil-mediated damage to schistosomula of Schistosoma mansoni in vitro: a study by phasecontrast and electron microscopy. J. Cell Sci. 34, 173-192.

Hagan, P., Moore, P.J., Adjukiewicz, A.B., Greenwood, B.M., Wilkins, H.A., 1985. In-vitro antibody-dependent killing of schistosomula of Schistosoma haematobium by human eosinophils. Parasite Immunol. 7, 617-624.

Hamann, K.J., Gleich, G.J., Checkel, J.L., Loegering, D.A., McCall, J.W., Barker, R.L., 1990. In vitro killing of microfilariae of Brugia pahangi and Brugia malayi by eosinophil granule proteins. J. Immunol. 144, 3166-3173.

Humbles, A.A., Lloyd, C.M., McMillan, S.J., Friend, D.S., Xanthou, G., McKenna, E.E., Ghiran, S., Gerard, N.P., Yu, C., Orkin, S.H., Gerard, C., 2004. A critical role for eosinophils in allergic airways remodeling. Science 305, 1776-1779.

Kassai, T., 1982. Handbook of Nippostrongylus brasiliensis (Nematode). Commonwealth Agricultural Bureaux, Slough, United Kingdom.

Kay, A.B., Moqbel, R., Durham, S.R., MacDonald, A.J., Walsh, G.M., Shaw, R.J., Cromwell, O., Mackay, J., 1985. Leucocyte activation initiated by IgE-dependent mechanisms in relation to helminthic parasitic disease and clinical models of asthma. Int. Arch. Allergy Appl. Immunol. 77, 69-72.

Khan, W.I., Abe, T., Ishikawa, N., Nawa, Y., Yoshimura, K., 1995. Reduced amount of intestinal mucus by treatment with anti-CD4 antibody interferes with the spontaneous cure of Nippostrongylus brasiliensis-infection in mice. Parasite Immunol. 17, 485-491.

Klion, A.D., Nutman, T.B., 2004. The role of eosinophils in host defense against helminth parasites. J. Allergy Clin. Immunol. 113, 30-37.

Kopf, M., Brombacher, F., Hodgkin, P.D., Ramsay, A.J., Milbourne, E.A., Dai, W.J., Ovington, K.S., Behm, C.A., Kohler, G., Young, I.G., Matthaei, K.I., 1996. IL-5-deficient mice have a developmental defect in CD5+ B-1 cells and lack eosinophilia but have normal antibody and cytotoxic $\mathrm{T}$ cell responses. Immunity 4, 15-24.

Korenaga, M., Hitoshi, Y., Yamaguchi, N., Sato, Y., Takatsu, K., Tada, I., 1991. The role of interleukin-5 in protective immunity to Strongyloides venezuelensis infection in mice. Immunology 72, 502-507.

Lee, T.D., 1991. Helminthotoxic responses of intestinal eosinophils to Trichinella spiralis newborn larvae. Infect. Immun. 59, 4405-4411.

Lee, J.J., Lee, N.A., 2005. Eosinophil degranulation: an evolutionary vestige or a universally destructive effector function? Clin. Exp. Allergy 35, 986-994.

Madden, K.B., Yeung, K.A., Zhao, A., Gause, W.C., Finkelman, F.D., Katona, I.M., Urban Jr., J.F., Shea-Donohue, T., 2004. Enteric nematodes induce stereotypic STAT6-dependent alterations in intestinal epithelial cell function. J. Immunol. 172, 5616-5621.

Maizels, R.M., Balic, A., Gomez-Escobar, N., Nair, M., Taylor, M.D., Allen, J.E., 2004. Helminth parasites - masters of regulation. Immunol. Rev. 201, 89-116.

Matthaei, K.I., Foster, P., Young, I.G., Hogan, S.P., Foster, P.S., Ramsay, A.J., 1997. The role of interleukin-5 (IL-5) in vivo: studies with IL-5 deficient mice. Mem. Inst. Oswaldo Cruz 92 Suppl 2, 63-68.

McNeil, K.S., Knox, D.P., Proudfoot, L., 2002. Anti-inflammatory responses and oxidative stress in Nippostrongylus brasiliensis-induced pulmonary inflammation. Parasite Immunol. 24, 15-22.

Meeusen, E.N., Balic, A., 2000. Do eosinophils have a role in the killing of helminth parasites? Parasitol. Today 16, 95-101.

Ogilvie, B.M., Parrott, D.M., 1977. The immunological consequences of nematode infection. Ciba Found. Symp. 46, 183-201.

Ovington, K.S., McKie, K., Matthaei, K.I., Young, I.G., Behm, C.A., 1998. Regulation of primary Strongyloides ratti infections in mice: a role for interleukin-5. Immunology 95, 488-493.

Parsons, J.C., Coffman, R.L., Grieve, R.B., 1993. Antibody to interleukin 5 prevents blood and tissue eosinophilia but not liver trapping in murine larval toxocariasis. Parasite Immunol. 15, 501-508.

Rajan, T.V., Ganley, L., Paciorkowski, N., Spencer, L., Klei, T.R., Shultz, L.D., 2002. Brugian infections in the peritoneal cavities of laboratory mice: kinetics of infection and cellular responses. Exp. Parasitol. 100, 235-247.

Ramalingam, T., Ganley-Leal, L., Porte, P., Rajan, T.V., 2003. Impaired clearance of primary but not secondary Brugia infections in IL-5 deficient mice. Exp. Parasitol. 105, 131-139.

Reece, J.J., Siracusa, M.C., Scott, A.L., 2006. Innate immune responses to lung-stage helminth infection induce alternatively activated alveolar macrophages. Infect. Immun. 74, 4970-4981.

Sakamoto, Y., Hiromatsu, K., Ishiwata, K., Inagaki-Ohara, K., Ikeda, T., Nakamura-Uchiyama, F., Nawa, Y., 2004. Chronic intestinal nematode infection induces Stat6-independent interleukin-5 production and causes eosinophilic inflammatory responses in mice. Immunology 112, 615-623.

Sanderson, C.J., 1988. Interleukin-5: an eosinophil growth and activation factor. Dev. Biol. Stand. 69, 23-29.

Sanderson, C.J., 1990. The biological role of interleukin 5. Int. J. Cell Cloning 8 (Suppl 1), 147-153.

Sanderson, C.J., 1992. Interleukin-5, eosinophils, and disease. Blood 79, 3101-3109.

Sasaki, O., Sugaya, H., Ishida, K., Yoshimura, K., 1993. Ablation of eosinophils with anti-IL-5 antibody enhances the survival of intracranial worms of Angiostrongylus cantonensis in the mouse. Parasite Immunol. 15, 349-354.

Sheridan, J.W., Finlay-Jones, J.J., 1977. Studies on a fractionated murine fibrosarcoma: a reproducible method for the cautious and a caution for the unwary. J. Cell Physiol. 90, 535-552.

Shinkai, K., Mohrs, M., Locksley, R.M., 2002. Helper T cells regulate type-2 innate immunity in vivo. Nature $420,825-829$.

Strath, M., Dent, L., Sanderson, C., 1992. Infection of IL5 transgenic mice with Mesocestoides corti induces very high levels of IL5 but depressed production of eosinophils. Exp. Hematol. 20, 229-234.

Sugane, K., Oshima, T., 1982. Eosinophilia, granuloma formation and migratory behaviour of larvae in the congenitally athymic mouse infected with Toxocara canis. Parasite Immunol. 4, 307-318. 
Sugane, K., Kusama, Y., Takamoto, M., Tominaga, A., Takatsu, K., 1996. Eosinophilia, IL-5 level and recovery of larvae in IL-5 transgenic mice infected with Toxocara canis. J. Helminthol. 70, 153-158.

Takamoto, M., Ovington, K.S., Behm, C.A., Sugane, K., Young, I.G., Matthaei, K.I., 1997. Eosinophilia, parasite burden and lung damage in Toxocara canis infection in C57Bl/6 mice genetically deficient in IL5. Immunology 90, 511-517.

Taliaferro, W.H., Sarles, M.P., 1939. The cellular reactions in the skin, lungs and intestine of normal and immune rats after infection with Nippostrongylus muris. J. Infect. Dis. 64, 157-192.

Tumes, D.J., Cormie, J., Calvert, M.G., Stewart, K., Nassenstein, C., Braun, A., Foster, P.S., Dent, L.A., 2007. Strain-dependent resistance to allergen-induced lung pathophysiology in mice correlates with rate of apoptosis of lung-derived eosinophils. J. Leukoc. Biol. 81, 1362 1373.

Urban Jr., J.F., Noben-Trauth, N., Donaldson, D.D., Madden, K.B., Morris, S.C., Collins, M., Finkelman, F.D., 1998. IL-13, IL4Ralpha, and Stat6 are required for the expulsion of the gastrointestinal nematode parasite Nippostrongylus brasiliensis. Immunity 8, 255-264.

Vallance, B.A., Matthaei, K.I., Sanovic, S., Young, I.G., Collins, S.M., 2000. Interleukin-5 deficient mice exhibit impaired host defence against challenge Trichinella spiralis infections. Parasite Immunol. 22, 487492.

Vaux, D.L., Lalor, P.A., Cory, S., Johnson, G.R., 1990. In vivo expression of interleukin 5 induces an eosinophilia and expanded Ly-1B lineage populations. Int. Immunol. 2, 965-971.

Yamaguchi, Y., Hayashi, Y., Sugama, Y., Miura, Y., Kasahara, T., Kitamura, S., Torisu, M., Mita, S., Tominaga, A., Takatsu, K., 1988. Highly purified murine interleukin 5 (IL-5) stimulates eosinophil function and prolongs in vitro survival. IL-5 as an eosinophil chemotactic factor. J. Exp. Med. 167, 1737-1742.

Yazdanbakhsh, M., van den Biggelaar, A., Maizels, R.M., 2001. Th2 responses without atopy: immunoregulation in chronic helminth infections and reduced allergic disease. Trends Immunol. 22, 372-377.

Yu, C., Cantor, A.B., Yang, H., Browne, C., Wells, R.A., Fujiwara, Y., Orkin, S.H., 2002. Targeted deletion of a high-affinity GATA-binding site in the GATA-1 promoter leads to selective loss of the eosinophil lineage in vivo. J. Exp. Med. 195, 1387-1395.

Zhao, A., McDermott, J., Urban Jr., J.F., Gause, W., Madden, K.B., Yeung, K.A., Morris, S.C., Finkelman, F.D., Shea-Donohue, T., 2003. Dependence of IL-4, IL-13, and nematode-induced alterations in murine small intestinal smooth muscle contractility on Stat6 and enteric nerves. J. Immunol. 171, 948-954. 